\title{
COVID-19 E O ACESSO TECNOLÓGICO DE PAIS E ALUNOS A EDUCAÇÃO REMOTA EM ESCOLAS PÚBLICAS E PRIVADAS
}

\author{
COVID-19 AND PARENTS AND STUDENT TECHNOLOGICAL ACCESS TO REMOTE EDUCATION \\ IN PUBLIC AND PRIVATE SCHOOLS
}

DOI: http://dx.doi.org/10.16891/2317-434X.v8.e3.a2020.pp785-792

Recebido em: 07.08.2020 | Aceito em: 26.08.2020

\begin{abstract}
Cicero Magerbio Gomes Torresa, Maria Naline Amorimb, Williany Alves Pereira Bezerrac, Francielton Amorim Marçald, Socorro Márcia Gomes Torrese
\end{abstract}

\author{
Universidade Regional do Cariria \\ Universidade de Pernambucob \\ Secretaria Municipal de Educação de Petrolina-PEc \\ Centro Universitário Doutor Leão Sampaiod \\ Secretaria Municipal de Educação do Crato \\ *E-mail: cicero.torres@urca.br
}

\section{RESUMO}

Em 2020 houve no Brasil a confirmação da infecção pelo SARS-CoV-2 em seres humanos, na qual a doença foi nomeada como o novo Coronavírus (COVID-19). O presente artigo apresenta uma análise dos resultados de uma pesquisa sobre a pandemia da COVID-19 e seus reflexos frente ao acesso tecnológico de pais e alunos a educação de escolas públicas e privadas. $O$ trabalho apresenta-se fundamentado na metodologia exploratória do tipo qualitativa realizada a partir de fontes secundárias relacionada com a literatura pertinente à temática. Considerou-se para isso artigos publicados na base de dados google scholar publicados no ano 2020, bem como livros e capítulos de livros eletrônicos sobre o Coronavírus e a educação pública e privada do Brasil. Os resultados explicitam as diferenças sociais e econômicas dos pais e respectivamente dos alunos frente ao acesso as tecnologias, as diferentes perspectivas das instituições de ensino público e privado em relação às ações para o desenvolvimento do ensino e as dificuldades dos pais quanto ao acompanhamento dos filhos tendo em vista a aprendizagem em meio à crise global da pandemia em nosso país. Conclui-se que a maioria das instituições de ensino público passa por dificuldades em termos políticos e estruturais, ao tempo que as instituições privadas têm despontado em relação ao ensino remoto haja vista a natureza autossustentável das mesmas. Pode-se perceber as dificuldades dos pais em relação às condições sociais e econômicas para aquisição de celulares, computadores compatíveis e aquisição de pacotes de internet, bem como a complexidade por residirem em locais de difícil acesso a internet. Desta forma a pandemia da COVID - 19 tem evidenciado desigualdades significativas quanto ao acesso à educação no país.

Palavras-chave: COVID-19; Pandemia; Educação; Processos Pedagógicos.

\section{ABSTRACT}

In 2020, in Brazil, SARS-CoV-2 infection in humans was confirmed, in which the disease was named as the new Coronavirus (COVID-19). This article presents an analysis of the results of a survey on the COVID-19 pandemic and its reflections on the technological access of parents and students to education in public and private schools. The work is based on an exploratory reflection perspective through secondary sources of literature relevant to the theme; considering articles from national journals, reporting and recent productions on Coronavirus and public and private education in Brazil. The results show the parents 'social and economic differences in terms of access to technologies, the perspective of public and private education institutions in relation to actions for the development of education and the parents' difficulties in monitoring their children with a view to learning in amid the global pandemic crisis in our country. It is concluded that the majority of public education institutions are experiencing difficulties in political and structural terms, while private institutions have emerged in relation to remote education due to their self-sustainable nature. It is possible to perceive the parents' difficulties in relation to the social and economic conditions for the acquisition of compatible cell phones and computers and the purchase of internet packages, as well as the complexity of living in places with difficult access to the internet. Thus, the COVID - 19 pandemic has shown significant inequalities in terms of access to education in the country.

Keyword: COVID-19; Pandemic; Education; Pedagogical Processes. 


\section{INTRODUÇÃO}

Em 2020 houve no Brasil a confirmação da infecção pelo SARS-CoV-2 em seres humanos, na qual a doença foi nomeada como o novo Coronavírus (COVID19). A doença cursa com quadros que variam de assintomáticos a respiratórios graves, cuja doença foi determinada como Emergência em Saúde Pública, pois a sua a transmissão acontece de pessoa a pessoa, ou seja, de fácil disseminação (BRASIL, 2020a).

As questões apresentadas no texto se relacionam com os desafios que a pandemia da COVID-19 tem apresentado aos pais e alunos quanto ao uso, acesso tecnológico e garantia da aprendizagem. Neste sentido, o texto tem como objetivo refletir sobre os desafios que a pandemia da COVID - 19 tem apresentado para o processo de ensino e de aprendizagem na atualidade, considerando para isso o conhecimento referente à prática pedagógica, elemento este fundamental para compreendermos o processo de aprendizagem dos alunos.

Nesta perspectiva, a conjuntura política, econômica, social, educacional, cultural e científica do Brasil se delineia de forma complexa e desafiadora no cenário estabelecido pela pandemia de COVID - 19. Com isso, o contexto educacional, por exemplo, passa por um processo de reorganização estrutural e metodológico ao tempo em que atravessa um caminho difícil em virtude do desmonte das políticas públicas educacionais. Discutir a educação, no âmbito deste contexto, torna-se desafiador e instigante, haja vista a necessidade de pensar bases sólidas para lutar a favor de uma educação pública, inclusiva, laica e de qualidade.

De forma a atender o objetivo da pesquisa o qual consiste em refletir sobre os desafios que a pandemia da COVID - 19 tem apresentado para o processo de ensino e de aprendizagem na atualidade, considerando para isso o conhecimento referente à prática pedagógica, elemento este fundamental para compreendermos o processo de aprendizagem dos alunos, o presente trabalho apresenta-se fundamentado na metodologia exploratória do tipo qualitativa realizada a partir de fontes secundárias relacionada com a literatura pertinente à temática. Considerou-se para isso artigos publicados na base de dados google scholar publicados no ano 2020, bem como livros e capítulos de livros eletrônicos sobre o Coronavírus e a educação pública e privada do Brasil.

EM TEMPOS DE PANDEMIA DO COVID - 19: PROBLEMATIZANDO O ACESSO DE PAIS E ALUNO AO ENSINO REMOTO A PARTIR DO CONTEXTO DAS ESCOLAS PÚBLICAS E PRIVADAS

Em dezembro de 2019 surgiu na China uma doença infecciosa causada por um novo vírus, na qual foi intitulada como COVID-19, que trouxe ao mundo um processo pandêmico que vem se estendendo desde sua origem até a atualidade. $\mathrm{O}$ surto, inicialmente estabelecido na China, trouxe muitos transtornos a quase todos os países do mundo, inclusive ao Brasil. Dentre esses transtornos, está o isolamento social, medida que restringiu as pessoas ao direito de ir e vir e consequentemente o afastamento dos estudantes do ambiente escolar com o objetivo de evitar aglomerações e a propagação do vírus (GLOBO, 2020).

Em virtude da pandemia do novo Coronavírus, a Organização das Nações Unidas para Educação, Ciências e Cultura-UNESCO (2020), recomendou o ensino remoto por meio de plataformas virtuais para minimizar o impacto no processo de educação das crianças, jovens e adultos.

O Ministério da Educação (MEC) homologa o Parecer CNE/CP no 5/2020, do Conselho Nacional de Educação - CNE, que tem o objetivo de orientar estados, municípios e escolas sobre as práticas que devem ser adotadas durante a pandemia, além de propor normas nacionais gerais para fins de cumprimento da carga horária mínima anual, em razão da pandemia do novo coronavírus (BRASIL, 2020b).

Embora se reconheça que em virtude das medidas adotadas os sistemas de ensino poderão ser afetados com impactos significativos de diferente formas para as classes sociais, em virtude da pandemia e, sobretudo, do isolamento social. Ao longo dos anos outras pandemias ocorreram, no entanto não resultou na necessidade de se estabelecer isolamento social. Estas não afetaram diretamente as escolas e o ensino como temos visto na atualidade, Desta forma, propor alternativas de forma imediatista seria transcorrer em uma perspectiva distante da inclusão, da sensibilidade, alteridade, igualdade e equidade.

Para Arruda (2020, p. 2),

O isolamento social promoveu transformações econômicas severas imediatas, com a parada obrigatória de inúmeros setores, modificou nossa relação com a arte, devido à ausência do compartilhamento presencial de experiências de fruição e, no caso da educação, promove desconstruções sob a forma como o ensino e a aprendizagem são vistos socialmente.

O novo coronavírus torna a escola um dos espaços mais temidos pelo risco da transmissão, pois a sua multiplicidade e heterogeneidade cria vínculos entre aqueles que são menos propensos aos sintomas graves da doença (jovens) a todos os demais que podem ser até mortalmente propensos. Crianças e jovens entram em 
contato diário com adultos de diferentes grupos familiares: professores, profissionais da educação, pais e mães, avós e avôs, parentes de maneira geral (ARRUDA, 2020).

Neste contexto, a utilização de ferramentas tecnológicas desprovidas de um planejamento pedagógico participativo, inclusivo, democrático não garante a qualidade do ensino que se almeja na constituição e a Lei de Diretrizes e Base da Educação 9.394/96 (BRASIL, 1996). Sabe-se que a aprendizagem não se dá por geração espontânea, e que a mesma não se dá por meio de soluções mágicas, nas quais a simples utilização de recursos digitais reforçam apenas os preceitos do que se conhece por instrução. A aprendizagem está para além da instrução. Desta forma o ensino remoto, apresenta-se como uma alternativa emergencial para o contexto, embora não substituía a importância da aula presencial, da interação e relações sociais que se desenvolve no âmbito do espaço escolar.

O termo "remoto" significa distante no espaço e se refere a um distanciamento geográfico (AURÉLIO, 2016). No contexto vivenciado o ensino remoto é um formato de escolarização mediado por tecnologia, mantidas as condições de distanciamento professor e aluno. Esse formato de ensino se viabiliza pelo uso de plataformas educacionais ou destinadas para outros fins, abertas para o compartilhamento de conteúdos escolares (GARCIA et al, 2020).

Embora esteja diretamente relacionado ao uso de tecnologia digital, ensinar remotamente não é sinônimo de ensinar a distância, considerando esta última uma modalidade que tem uma concepção teórico-metodológica própria e é desenvolvida em um ambiente virtual de aprendizagem, com material didático-pedagógico específico e apoio de tutores (GARCIA et al, 2020). A modalidade de ensino remoto vai ao encontro da proposta de período suplementar excepcional e pressupõe o planejamento de componentes curriculares do ensino presencial para o formato remoto (GARCIA et al, 2020).

O Ensino a Distância (EaD) possui uma estrutura política e didática-pedagógica que busca englobar de maneira flexível toda uma gama de conteúdos e atividades para cada disciplina, de acordo com objetivos e características dos conhecimentos e das habilidades gerais, assim como possui legislação especifica. A EaD permite que o aluno organize o seu próprio horário de aula, no entanto, o ensino remoto preconiza a transmissão em tempo real das aulas, ou seja, ao vivo. A ideia é que professor e alunos de uma turma tenham interações nos mesmos horários em que as aulas da disciplina ocorreriam no modelo presencial (SAE DIGITAL, 2020).

No Brasil, o ensino por correspondência e por programas de TV e rádio podem ser consideradas as primeiras iniciativas formais de Educação a Distância. Os computadores chegaram ao Brasil, no campo educacional, por meio das universidades, que instalaram as primeiras máquinas na década de 1970. Posteriormente, já disponível nos computadores pessoais, a Internet ajudou a consolidar a propagação da EAD para todo o sistema educativo brasileiro (MATURANO e LEMOS, 2012).

Em relação as primeiras legislações sobre a Educação a Distância, Maturano e Lemos (2012) salientam que estas surgiram na década de 1960, destacando o Código Brasileiro de Comunicações (Decreto-Lei $n^{\circ}$ 236/67) e a Lei de Diretrizes e Bases da Educação Nacional (Lei 5.692/71), sendo que essa última possibilitava que o ensino supletivo fosse ministrado mediante a utilização do rádio, televisão, correspondência e outros meios de comunicação (MATURANO e LEMOS, 2012).

Porém, nos anos de 1990, tem-se a promulgação da Lei de Diretrizes e Bases da Educação Nacional (LDB 9.394/96), responsável, por entre outros motivos, em dar um novo status à EAD, atribuindo-lhe legitimidade e visibilidade (MATURANO e LEMOS, 2012).

Em maio de 2017, o decreto $\mathrm{n}^{\circ}$ 9.057, passou a regulamentar em seu Art. $1^{\circ}$ que a educação a distância entendida como, modalidade educacional na qual a mediação didático-pedagógica dos processos de ensino e aprendizagem ocorra com a utilização de meios e tecnologias de informação e comunicação, com pessoal qualificado, com políticas de acesso, com acompanhamento e avaliação compatíveis, entre outros, e desenvolva atividades educativas por estudantes e profissionais da educação que estejam em lugares e tempos diversos.

Embora essa modalidade de ensino tenha uma longa história no Brasil, as primeiras iniciativas na área de ensino superior só surgiram na década de 1990, motivadas pela percepção de que a Educação a Distância era uma estratégia que poderia operar paralelamente à escola regular (MATURANO e LEMOS, 2012).

Neste sentido, compreende-se que os impactos serão abrangentes, porém torna-se necessário ampliar o debate de forma democrática, para pensarmos coletivamente e colaborativamente novas possibilidades de ensino de forma que garanta o vínculo com a escola, com os professores, com os alunos e com a vida, elemento primordial e essencial neste momento de crise e desta forma evidenciar as significativas diferenças entre ensino remoto e educação a distância $(\mathrm{EaD})$.

Em um contexto complexo e imprevisível, no qual o mundo aprende a lidar com os desafios impostos pela pandemia do novo coronavírus no cotidiano, tem-se percebido que as escolas buscam, dentro de suas condições estruturais se reinventarem coletivamente a encontrar caminhos para o enfrentamento do maior problema sanitário do século XXI (PORVIR, 2020). Superar os desafios impostos pela pandemia da COVID - 19 implica 
em, usar a criatividade, as novas tecnologias, exercer a alteridade, utiliza-se da sensibilidade e compreender as questões sociais, políticas, econômicas e culturais dos pais.

Corroboramos com os autores Hodges et al. (2020) quando afirmam que a educação remota online digital se diferencia da Educação a Distância pelo caráter emergencial que propõe usos e apropriações das tecnologias em circunstâncias especificas de atendimento onde outrora existia regularmente a educação presencial (ARRUDA, 2020).

Neste sentido, o ensino remoto, opção escolhida pela maioria das escolas de forma emergencial, tem evidenciado desafios aos pais, uma vez que a ação de ensinar exige formação especializada, em cursos de licenciatura, bem como estudos e aprofundamentos teóricos e práticos sobre a ação docente.

O ensino remoto é um desafio para pais, alunos, escola e professores uma vez que exige que todos tenham habilidades e iniciativa para contornar os problemas, ou ao menos, enfrentá-los de forma positiva e criativa. Mesmo distanciados pelo tempo e pelos espaços físicos é possível que haja uma integração ajustada e interativa (DELORS, 2013).

Aos pais, fica a responsabilidade de acompanharem e quando não possível, ao menos incentivarem os filhos. Aos alunos, fica a necessidade de buscarem o conhecimento que lhes são oferecidos e de buscar ressignificar os mesmos. À escola, fica o encargo de fornecer aos professores ferramentas simples e instrucionais através de tutoriais, mantendo uma equipe de suporte adequado para auxiliar nesse processo.

Aos professores, solicita-se ampliar suas práticas educativas e o desenvolvimento de habilidades para ensinar em parceria com a tecnologia e também com a falta dela; facilitar a interação; aprender e se adaptar ao uso das mídias sociais e desses ambientes digitais; provocar nos alunos a busca pelo conhecimento com as ferramentas corretas e possíveis; e estar disposto a conhecer novas

Conforme destaca o Parecer no 0205/2020 do Conselho Estadual de Educação do Estado do Ceará,

A pandemia tem revelado fragilidades dos sistemas de ensino e das instituições escolares e, também, evidenciado a necessidade de mudanças urgentes na sua organização, na formação dos professores e técnicos da educação e no fazer pedagógico cotidiano. Reconhece, por outro lado, que a pandemia está descortinando a capacidade criativa e a resiliência dos professores, assim como a participação e a autonomia dos estudantes para encontrarem alternativas de superação das dificuldades pedagógicas e tecnológicas e minimizar maiores prejuízos. Nesse sentido, o apoio dado pelos familiares dos estudantes tem formas de educar, fazendo a educação e a tecnologia andarem juntas para assim alcançarem todos os objetivos propostos (DELORS, 2013).

Percebe-se com isso que independentemente do nível de escolaridade dos pais ou se a instituição seja pública ou privada, o ato de ensinar não consiste no simples "dom" como afirmavam os jesuítas durante o apogeu do Ratio Studiorum (1599 - 1759), desta forma compreende-se os desafios que os pais tem apresentado em relação a utilização de recursos tecnológicos para colaborarem com a aprendizagem. Implícito aos desafios, à utilização das novas tecnologias, incide ainda condições econômicas dos pais para garantirem o acesso dos filhos aos recursos tecnológicos, tais como, internet, notebooks, dados móveis, dentre outros.

Porém, percebe-se que os encaminhamentos relacionados às escolas públicas e privadas desenvolveram-se de forma amplamente diferenciadas. As escolas privadas, por suas especificidades, gestadas pelo Ministério da Educação (MEC) optaram pela realização de aula remota, conforme preconiza as resoluções publicadas pelo Ministério da Educação (MEC), tais como a Portaria $\mathrm{n}^{\mathrm{o}} 343$, de 17 de março de 2020 e a portaria $n^{\circ} 544$, de 16 de junho de 2020.

Para isso investiram necessariamente na compra de software e consideravelmente na aquisição de recursos tecnológicos para subsidiar e garantir a clientela de alunos, uma vez que, do contrário, possivelmente, poderiam incorrer no trancamento elevado de matrícula/evasão por parte dos pais/alunos.

As escolas públicas, diferentemente das escolas particulares são legisladas pelas secretarias municipais e conselhos estaduais, o que gera com isso, uma diferença estrutural significativa em termos operacionais, pois, na sua maioria as escolas particulares possuem recursos próprios para se manterem e investir em recursos tecnológicos. Diferentemente das escolas publicas que dependem diretamente dos governos, municipais, estaduais e federal para se manterem.

sido imprescindível, sem o que seria inviável a manutenção das atividades remotas como alternativa para evitar a perda de aprendizagens e o cancelamento do ano letivo (CONSELHO ESTADUAL DE EDUCAÇÃO DO ESTADO DO CEARÁ, 2020, p. 2)

Desta forma, coube aos municípios e aos estados regulamentarem, como seria o processo de aprendizagem dos alunos, uma vez que, os desafios estruturais, econômicos e de formação continuada, apresentam-se de forma diferente do contexto vivenciado pelas escolas particulares.

Ressalta-se, neste contexto, perceber as diferenças apontadas anteriormente sobre o ensino remoto oferecido pelas escolas privadas, o qual foi 
amplamente impulsionado do ensino remoto oferecido pelas escolas públicas, considerando para isto à desvalorização da educação pública em tempos de pandemia.

Conforme analisa Arruda (2020, p. 6),

As instituições privadas, como os grupos Kroton, Estácio e Unip, bem como Universidades tradicionais, representadas pelas Pontifícias Universidades Católicas de todo o país, definiram retorno às aulas mediado por tecnologias desde o mês de março. A maioria das instituições investigadas buscaram implementar educação remota, de maneira a diferenciar-se da modalidade EaD. Neste formato, as aulas são transmitidas em tempo instantâneo por sistemas de webconferências, as chamadas lives, que permitem que professores e alunos tenham condições de realizar interações e organizarem seus tempos de aprendizagem da forma mais próxima à educação presencial.

Vale ressalta-se que as escolas públicas, em nenhum momento deixaram o ensino apenas para quando acabasse o isolamento social, pelo contrário, as escolas públicas otimizaram a partir do contexto vivenciado, de sua realidade social, econômica, estrutural, colocar-se no lugar do outro, praticar a alteridade, defender o ensino para todos, de forma democrática, colaborativa e participativa, o que não implica em dizer que a escola privada não tenha procedido da mesma forma.

No entanto, compreende-se que, no âmbito do contexto capitalista, a prerrogativa defendida pela escola privada em permanecer de forma imediatista com o ensino remoto, chamou atenção face à complexidade do vírus. Embora a opção pelo ensino remoto tenha sido uma estratégia emergencial para o referido contexto, reconhece-se a importância dessa iniciativa para a manutenção das relações entre a escola e os alunos, embora se ratifique a necessidade de não confundirmos o ensino com a instrução.

Para Libâneo (1994) a instrução se refere à formação intelectual, formação e desenvolvimento das capacidades cognoscitivas mediante o domínio de certo nível de conhecimentos sistematizados. Desta forma, o ensino corresponde a ações, meios e condições para realização da instrução, ou seja, o ensino contém, pois, a instrução.

$\mathrm{O}$ autor ratifica ainda que existe uma relação de subordinação da instrução à educação, uma vez que o processo e o resultado da instrução são orientados para o desenvolvimento das qualidades específicas da personalidade. Portanto, reitera o autor, a instrução, mediante o ensino, tem resultados formativos quando converge para o objetivo educativo, isto é, quando os conhecimentos, habilidades e capacidades propiciados pelo ensino se tornam princípios reguladores da ação humana, em convicção e atitudes reais frente à realidade (LIBÂNEO, 1994).

Libâneo (1994) destaca ainda que existe uma unidade entre educação e instrução, embora sejam processos diferentes; pode-se instruir sem educar, e educar sem instruir; conhecer os conteúdos de uma matéria, conhecer os princípios morais e normas de conduta não leva necessariamente a praticá-los, isto é, a transformá-los em convicções e atitudes efetivas frente aos problemas e desafios da realidade. Cumpre acentuar, entretanto, para o autor que o ensino é o principal meio e fator da educação, ainda que não o único, e por isso, destaca-se como campo principal da instrução e da educação (LIBÂNEO, 1994).

Os pais dos alunos matriculados nas instituições públicas, embora reconheçam as dificuldades vivenciadas por eles, e por reconhecer o descaso que a educação brasileira tem passado, manifestam preocupações em relação à aprendizagem dos filhos, haja vista o pouco investimento aplicado às escolas, às novas tecnologias, à formação de professores e à qualidade da educação.

Sabe-se que muitas crianças da rede pública são de classe média e baixa, dessa forma, entende-se que os aspectos econômicos são de grande relevância para a aquisição de aparelhos tecnológicos e internet no ambiente domiciliar e esses são importantes para que ocorra a efetivação das aulas remotas (PNAD, 2018).

De acordo com dados da Pesquisa Nacional por Amostra de Domicílios (PNAD) do último trimestre de 2018, o percentual de jovens estudantes, com 14 anos ou mais que possuem acesso à internet, ultrapassa $95 \%$ nas três primeiras regiões, $81 \%$ na região Norte e $86 \%$ na região nordeste. Quando se incluem os jovens entre 10 e 13 anos, os percentuais mantêm-se na faixa de $92 \%$ nas regiões Sul, Sudeste e Centro Oeste e cai para $71 \%$ na região Norte e $79 \%$ na região Nordeste (ARRUDA, 2020).

De acordo com Arruda (2020, p. 14),

Em termos de universalização do acesso à internet, é possível inferir a emergência de uma política nacional de acesso à rede de banda larga móvel, a partir de envolvimento de grupos privados de telefonia móvel que já possuem políticas de disponibilização de pacotes de dados que não contabilizam o gasto de dados em determinados aplicativos, como Whatsapp e Facebook. Tal política pode ser ampliada para sites específicos determinados por secretarias de estado de Educação ou o Ministério da Educação, de maneira a permitir 
o amplo acesso a conteúdo educacional produzido.

Entende-se que as consequências que esse processo poderá trazer para o desenvolvimento das crianças e adolescentes, assim como para o desenvolvimento da sociedade, se alinham diante do contexto em que se nega a ciência e se minimiza a importância da educação.

Em termos sociais, o distanciamento das crianças das escolas, poderá dificultar a interação com os outros colegas, no entanto colocar a saúde das crianças e jovens adolescentes em risco, não é o melhor caminho diante de uma doença que não se tem um tratamento específico e vacina.

A pandemia deixará efeitos sobre o modo de aprender e ensinar. $\mathrm{O}$ isolamento modificou tanto $\mathrm{o}$ convívio familiar quanto à importância da utilização das novas tecnologias nas instituições de ensino. Estamos percebendo, durante o período de distanciamento social, período este denominado de quarentena, o quanto a tecnologia educacional aliada aos princípios pedagógicos e educacionais apresenta-se como um instrumento importante para a mediação do conhecimento.

Conforme enfatiza Arruda (2020, p. 3),

Mais do que um problema educacional, o bloqueio do acesso à escola reconfigurou a sociedade, na medida em que tempos e movimentos foram desconstruídos, famílias passaram a coadunarem as responsabilidades do trabalho e da vida dos estudantes em tempos ampliados e em contexto ora da necessidade da manutenção do emprego e da renda, ora no contexto de confinamento em espaços razoavelmente reduzidos, de maneira ao isolamento ser cotidianamente comparado a situações de Guerra.

As novas formas de ensinar no pós-pandemia do COVID - 19 nos fará refletir sobre a utilização pedagógica das novas tecnologias e sua incorporação de forma mais ampliada na prática docente, assim como outras áreas tem apresentado inovações, a exemplo do exposto, a medicina com consultas de telemedicina, a área jurídica com pareceres on-line, a biotecnologia com exames laboratoriais com a utilização de máquinas sofisticadas, dentre outras áreas. No entanto reitera-se a importância de priorizar a ciência e a educação de qualidade no país.

A pandemia do COVID - 19 determinou, uma inversão no fluxo do conhecimento. Se antes o sentido era da escola para a comunidade, hoje é o mundo exterior que invade a escola. Assim, a escola pode não ter mudado; entretanto, pode-se afirmar que ela foi mudada. Possivelmente não afirmaríamos isso há 20 anos.

Ressalta-se a importância da interação e do convívio social na escola como base para educação, no entanto, a obrigatoriedade de estar em casa nesse tempo, no faz refletir sobre a colaboração dos pais, dentro de suas limitações, na aprendizagem dos filhos em casa e desta forma manter a interação. A experiência do ensino on-line apresenta-se como uma opção emergencial. A percepção de que o conhecimento pode ser produzido dentro ou fora da escola traz uma nova significação para a educação. As escolas terão a oportunidade de discutir democraticamente com os professores, pais e comunidade acadêmica sobre novas possibilidades de aprendizagem.

\section{CONSIDERAÇÕES FINAIS}

Por meio dessa pesquisa, observou-se que existem grandes desafios que perpassam o ensino público, principalmente quanto à disponibilidade de internet e dados móveis para a população, bem como celulares compatíveis ou não com os programas disponibilizados para ocorrência do ensino remoto.

A interrupção das atividades presenciais nas escolas desdobram-se em grandes desafios para o ensino público, devido às condições de estrutura, econômica, tecnológicas, formação continuada, financiamento dentre outros fatores.

As escolas privadas, fundamentadas nas orientações do Ministério da Educação, ancoradas nos princípios mercadológicos, optaram por dar continuidade ao calendário escolar sem deliberações democráticas com os docentes e comunidade acadêmica. Estas investiram recursos próprios na aquisição de plataformas e ambientes virtuais de aprendizagem. Ressalta-se aqui um ponto importante quando comparada as escolas públicas, bem como o perfil sócio econômico dos clientes que fazem uso dos serviços ofertados pelas escolas privadas.

Em tempo, a pandemia do COVID - 19 revela de forma bastante clara o quanto estudantes de baixa renda são prejudicados quanto a aquisição de computador, tablet ou smartphone, internet e banda larga. Vale destacar, que a maioria dos alunos do ensino público são oriundos de famílias de baixa renda e nem todos os alunos têm igual acesso à internet e à recursos digitais.

Reconhece-se que o momento atual é de grande sofrimento para todos e, particularmente, para os estudantes e seus familiares, professores e demais profissionais da educação, mas que com coragem, liberdade, responsabilidade e cuidado, continuar 
criando, produzindo, ensinando e aprendendo, com a clareza que as instituições de ensino, firmam-se e se reinventam nas relações interpessoais e cooperativas, ao tempo em que ratifica-se que nada substituirá o professor e a energia que o liga ao estudante (CONSELHO ESTADUAL DE EDUCAÇÃO DO CEARÁ, 2020).

Desta forma, compreende-se a partir da pesquisa, o impacto da pandemia do COVID - 19 para as escolas públicas e privadas. Para a escola, alunos e pais os dias são desafiadores, pois para os que não têm acesso a tecnologia, esperar-se-ia a criação de recursos emergenciais, tais como, a criação de pacotes gratuitos de internet para plataformas online, videoaulas em redes sociais, whatsApp, blogs e materiais impressos para quem não tem acesso às novas tecnologias.

Portanto, é preciso neste momento, escutar como estão os alunos; fortalecer os laços e os diálogos; investir na formação de professores, inicial e continuada; sermos capazes de aprender permanentemente para assim fazermos das nossas escolhas menos exclusão.

Com isso ressalta-se o trabalho dos professores das escolas privadas e públicas que em meio a todas as dificuldades vêm buscando enfrentar o contexto de pandemia com alteridade ao tempo em que os desafios vivenciados pelas escolas públicas e escolas privadas, em plena pandemia do COVID-19, precisam ser valorizados, incentivados para assim construírem um ensino laico de qualidade que tão se almeja socialmente.

\section{REFERÊNCIAS}

ARRUDA, Eucidio Pimenta. Educação Remota Emergencial: elementos para políticas públicas na educação brasileira em tempos de Covid-19. EmRede. v. 7, n. 1, p. 257-275, 2020.

BRASIL. Brasília: Ministério da Saúde. Secretaria de Atenção Especializada à Saúde. Departamento de Atenção Especializada e Temática. CoordenaçãoGeral do Sistema Nacional de Transplantes. Nota Técnica $\mathbf{n}^{\circ} 25$, de 25 de março de 2020a. Disponível em:

http://portal.anvisa.gov.br/documents/2857848/5680 794/SEI_MS+-+0014073431+-

+Nota+T\%C3\%A9cnica+25_2020.pdf/1d8329cfd534-437d-bab5-629fd95bc5cf.

BRASIL. Ministério da Educação. Despacho de 29 de maio de 2020b. Disponível em: http://pesquisa.in.gov.br/imprensa/jsp/visualiza/inde $\mathrm{x} . \mathrm{jsp}$ ?data=01/06/2020\&jornal $=515 \&$ pagina $=32$.

BRASIL. Ministério da Educação. Portaria nº 343, de 17 de março de 2020.

BRASIL. Ministério da Educação. Portaria n ${ }^{\circ}$ 544, de 16 de junho de 2020.

BRASIL. Decreto $n^{\mathbf{0}}$ 9.057, de 25 de maio de 2017. Regulamenta o art. 80 da Lei $n^{\circ} 9.394$, de 20 de dezembro de 1996, que estabelece as diretrizes e bases da educação nacional. Disponível em: http://www.planalto.gov.br/ccivil_03/_Ato2015-

2018/2017/Decreto/D9057.htm. Acesso em: 25 abr. 2020

\section{CONSELHO ESTADUAL DE EDUCAÇÃO DO ESTADO DO CEARÁ. Parecer $\mathbf{n}^{\mathbf{0}} \mathbf{0 2 0 5 / 2 0 2 0 .}$}

COVID-19: 10 recomendações para planejar soluções de aprendizagem a distância. UNESCO. Disponível em: https://pt.unesco.org/news/covid-1910-recomendacoes-planejar-solucoes-aprendizagemdistancia. Acesso em: 13 jun. 2020.

GARCIA; Tânia Cristina Meira; MORAIS; Ione Rodrigues Diniz; ZAROS, Lilian Giotto; RÊGO, Maria Carmem Freire Diógenes. Ensino Remoto Emergencial: orientações básicas para elaboração do plano de aula [recurso eletrônico]. Natal: SEDIS/UFRN, 2020.

HODGES, Charles et al. The difference between emergency remote teaching and online learning. EDUCAUSE Review. 27 mar. 2020. Disponível em: https://er.educause.edu/articles/2020/3/thedifference-between-emergency-remote-teachingand-online-learning, 2020. Acesso em: 11 maio 2020.

IBGE. Pesquisa Nacional por Amostra de Domicílios (PNAD), 2018. 
LIBÂNEO, J. C. Didática. São Paulo: Cortez, 1994.

MATURANO, Ediane Carolina Peixoto Lopes; LEMES, Sebastião de Souza. Breves Discussões Sobre a Educação a Distância e as Políticas Públicas dos anos noventa até o momento atual. Revista Eletrônica Gestão \& Saúde. Edição Especial. p. 1266 - 1280, dezembro/2012.

O QUE MUDA NAS ESCOLAS APÓS A CRISE

DO CORONAVÍRUS? Disponível em: https://porvir.org/o-que-muda-nas-escolas-apos-acrise-do-coronavirus/ Acesso em: 20 jun. 2020.

O QUE SÃO AULAS REMOTAS? Disponível em: https://sae.digital/aulas-remotas/. Acesso em: 12 jun. 2020.

NOVO VÍRUS QUE CAUSA DOENÇA PULMONAR MISTERIOSA GERA TEMOR NA CHINA, MAS HÁ MOTIVO PARA PREOCUPAÇÃO? Disponível em: https://g1.globo.com/ciencia-eem: DIGITAL? DESAFIOS DA EDUCAÇÃO. Disponível em: saude/noticia/2020/01/13/novo-virus-que-causadoenca-pulmonar-misteriosa-gera-temor-na-chinamas-ha-motivo-para-preocupacao.ghtml. Acesso em: https://desafiosdaeducacao.grupoa.com.br/quaishabilidades-um-professor-precisa-ter-para-ensinarmundo-digital/_Acesso em: 23 jun. 2020.

5 jun. 2020. 